\title{
The ELVITEN Project as Promoter of LEVs in Urban Mobility: Focus on the Italian Case of Genoa
}

\author{
Francesco Edoardo Misso, Irina Di Ruocco, and Cino Repetto
}

\begin{abstract}
One of the growing innovations in the electric vehicle market concerns light electric vehicles (LEVs), promoted at local and national level by many initiatives, such as the European project ELVITEN, involving six cities, which is analysed in the present paper in relation to the Genoa pilot case study. In Italy, LEVs have been increasingly successful, as the number of their registrations shows (+76\% in 2019 compared to 2018). In this context, the city of Genoa, where a considerable fleet of mopeds and motorcycles $(214,499$ in its metropolitan area in 2018) circulates, lends itself well to the experimentation of two-wheeled LEVs. The monitoring of the use of LEVs within the framework of the ELVITEN project has shown that the average daily round trips recorded in the metropolitan area of Genoa are equal to $15-20 \mathrm{~km}$, thus reinforcing the idea that LEVs represent a valid alternative to Internal Combustion Engine (ICE) private vehicles. Moreover, the characteristics of the travel monitored and the users' feedback highlight that the question of range anxiety is less present than expected. Finally, and contrary to our expectations, the data analysis indicates that the use of LEVs in Genoa during two months of Covid-19 pandemic lockdown-March and April 2020-shows a decrease of $21 \%$, while the average decrease recorded by the six cities globally considered is $51 \%$.
\end{abstract}

Keywords LEVs • E-mobility • Genoa

\section{The ELVITEN Project}

The new frontiers of mobility include a number of new transport models, starting from the use of electric vehicles, micro-mobility or soft mobility systems up to electric self-driven vehicles, allowing environmentally friendly transit. Such models, which play an important role in the smart mobility scenario, require a solid

F. E. Misso $(\varangle) \cdot$ I. Di Ruocco · C. Repetto

T Bridge S.p.A, Via G. Garibaldi 7/10, 16124 Genoa, Italy

e-mail: f.misso@tbridge.it

(C) The Author(s) 2021

A. Ewert et al. (eds.), Small Electric Vehicles,

https://doi.org/10.1007/978-3-030-65843-4_5 
digitalisation. In this line, many cities have adopted new transport systems based on electric mobility, encouraging the use of light electric vehicles (LEV). The ELVITEN project ${ }^{1}$ (Electrified L-category Vehicles Integrated into Transport and Electricity Networks) aims at the diffusion and simultaneous integration of LEVs (e-bicycles, e-scooters, e-tricycles and quadricycles) in order to offer a new concept of sustainable urban transport system for people mobility (work, tourism, and leisure) and goods delivery. The ELVITEN project moved its first steps in 2017 thanks to Horizon 2020 funding. The project involves 21 partners, coordinated by the lead partner ICCS (Institute of Communication and Computer Systems) in Athens, including $\mathrm{T}$ Bridge that has the role of the coordinator for developing the ICT tools supporting the experimentation.

The ELVITEN project methodology proposes, implements, and demonstrates innovative deployment schemes to address in a comprehensive way all major issues related to the market entry of LEVs. These issues are poor user awareness due to a low level of information on vehicle performance and functionality, consumer concerns such as range anxiety, and inadequate mobility planning for LEVs of existing paid infrastructure networks and inadequate planning for the integration of LEVs into urban transport networks.

The approach of the project includes the preparation, usage, and analysis phases, analysing the mobility demand in six pilot cities (Berlin in Germany, Bari, Genoa and Rome in Italy, Malaga in Spain, and Trikala in Greece) and the identification of the usage schemes and potential number of users on the basis of each city's mobility conditions. In order to create profiles of potential ELVITEN users in each city, the project provides a focus on the following clusters of LEV users: systematic urban commuters, occasional urban travellers, and light delivery companies.

The actions are carried out in the demonstration cities and are related to the use of vehicles (e.g. parking lots or charging areas) focusing on the most strategic areas such as covered areas close to, for example, railway stations or shopping centres.

The ongoing activities include the set-up of a platform and applications for mobile devices through which citizens can, among others, access ELVITEN services, book charging points, and use sharing services in an integrated logic.

To summarise, the ELVITEN project aims at:

- testing how to enhance/reinforce electric vehicle use in the six pilot cities, reducing pollutant emissions as well as traffic congestion, targeting both cars and light vehicles (motorcycles, pedal-assisted bicycles, tri- and quadricycles);

- increasing LEV usage in urban areas, through the development of replicable usage schemes;

- deploying LEV innovative parking and charging services, to facilitate LEV owners;

- empowering LEV sharing and rental services;

- developing support ICT tools to motivate the usage of LEVs instead of ICE vehicles;

\footnotetext{
${ }^{1}$ www.elviten-project.eu/it/ [1].
} 
- understanding which factors can favour (or discourage) users' choices towards such kinds of vehicles.

The main purpose of the present paper is to show, in the light of the ELVITEN experience carried out in the pilot city of Genoa-which has 575,577 inhabitants [2] and is squashed between the Apennines and the Ligurian Sea-that LEVs are a viable and sustainable alternative, both for individual use and for sharing. We also focus on the observation of market trends in LEV trade and on initiatives related to the promotion of electric mobility such as the design of parking lots and parking areas for LEVs.

\section{The Current Trend in the LEV Sector}

Since 2017, there has been a growing diffusion of LEVs in Europe. In Italy, for example, this trend was demonstrated by the increase of the registrations of all categories of electric vehicles (EV), with a growth of $104 \%$ in 2018 compared to the previous year (see Fig. 1) [3, 4].

Italy, as other countries in Mediterranean Europe [5], is characterised by a massive use of two-wheeled vehicles (motorcycles, mopeds). In the first half of the year 2019, an increase of $135 \%$ and of $64 \%$ regarding the registrations of electric motorcycles (1,163 units) and e-mopeds (2,022 units), respectively, was observed in comparison with 2018 (see Fig. 2) [5].

Another performance that is worth highlighting is the growth in the number of charging points for EVs in Italy: 13,721 in February 2020 (there were 10,647 in September 2019) and 7,203 charging stations (425 in the Liguria Region) accessible to the public $(5,246$ in 2019) [6]. Of the total number of charging stations, $73 \%$ are located on public ground, while $27 \%$ are located on private areas open to the public, such as supermarkets or shopping centres [6].

At the national level, the current guidelines to support LEVs in Italy are the Decreto Ministeriale (Ministerial Decree) no. 229/2019 [8] that launched the experimentation of electrical micro-mobility, and the Piano Nazionale Infrastrutturale per la Ricarica dei veicoli alimentati ad Energia elettrica (PNIRE)

Fig. 1 Thousands of registrations of BEVs (battery electric vehicles) and PHEVs (plug-in hybrid electric vehicles) in Italy [3]

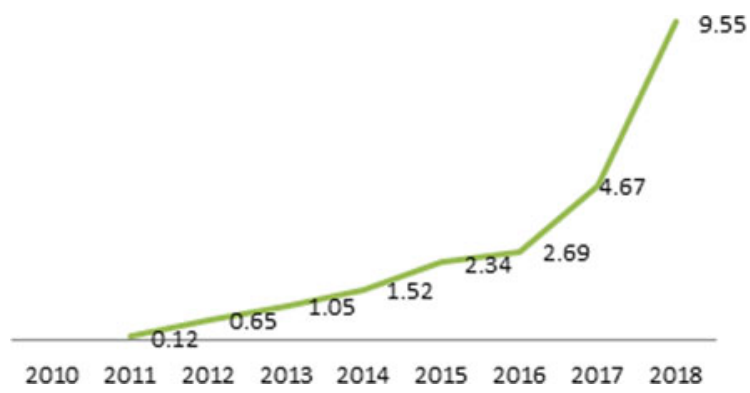




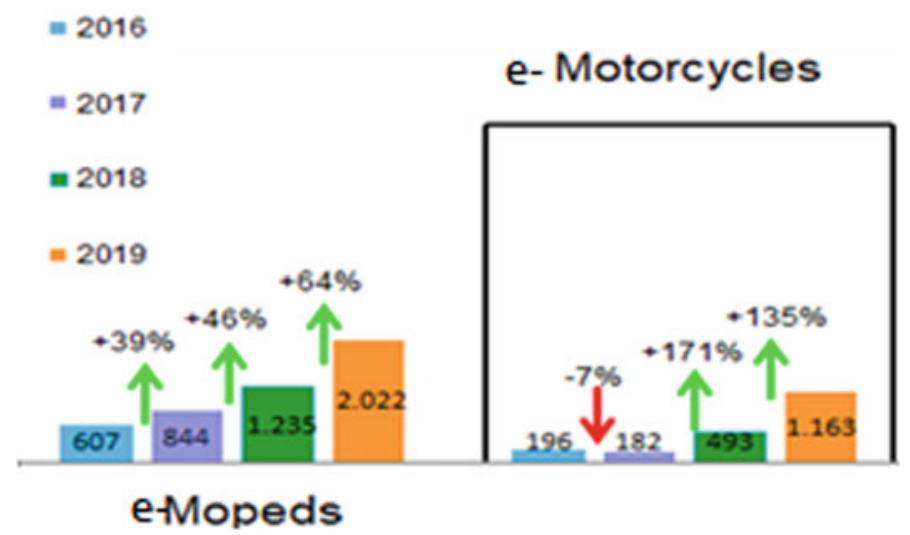

Fig. 2 Trend of the electric two-wheeled vehicles Italian market, 2016-2019 [5]

(National Infrastructure Plan for the Recharging of Electric-powered vehicles) [9] promoted by the Italian Ministry of Infrastructure and Transport (MIT) [7]. At the international level, the landmarks are the European Regulation no. 168/2013, that aims to establish harmonised rules for the type-approval of L-category vehicles, and the Transport 2050 Strategy [10, 11], that outlines a roadmap for a competitive transport sector with ambitious sustainability targets, such as reduction in $\mathrm{CO}_{2}$ emissions and fleet renewals to reach $100 \%$ of electric and hybrid vehicles.

Finally, the increasing use of ICT in sustainable mobility has played an important role in the transport sector promoting the shift from the central role of the hardware component (e.g. vehicles, roads, or infrastructures) towards a mobility model that serves the needs of the users. Therefore, ICT is becoming a strong support for public administrations and for users in the field of electric mobility to integrate EVs and LEVs globally with the transport network, especially in the framework of Mobility as a Service (MaaS). In this light, the MaaS model becomes eMaaS [12] in order to optimise the use of electric vehicles and overcome the disadvantages of "traditional" mobility and "traditional" sharing.

\section{The Case Study of Genoa}

The city of Genoa is the first large urban area with the highest number of ICE light vehicles in circulation in Italy and has one of the highest ratios of light vehicles per inhabitant in Europe, of over 26 LEVs per 100 inhabitants [13].

Indeed, motorcycles and mopeds make more than 28,000 trips per working day while cars about 47,000. Data on vehicle fleets from the Automobile Club of Italy (ACI) highlight about 397,111 light vehicles (motorcycles and mopeds) in the Liguria Region, 218,066 in the entire metropolitan area of Genoa and 144,970 in the city of Genoa [14]. 
Still, the use of electric scooters and quadricycles is low, and this is due to the persistence of psychological and technological barriers, such as asymmetric information, range anxiety, and charging operations (ELVITEN project, 2017, also based on previous experiences).

Moreover, the topographic characteristics of Genoa, with considerable differences in altitude and traffic-restricted streets in the historical centre, make this city, among the other European and Italian cities, suitable to be chosen as a pilot case to experiment the spread of electric vehicles in the framework of the ELVITEN project.

Since 2013, the City of Genoa has put in place several actions, which testify to the strong commitment of the city in the field of LEVs. Thanks to projects in which Genoa is the protagonist, these measures include the spread of the network of charging points and the launch of LEVs such as two-, three-, and four-wheel vehicles on the metropolitan territory.

ELVITEN is surely an example of such projects. It follows the legacy of the Ele. C.Tra. "Electric City Transport" project, funded by the IEE programme (Intelligent Energy-Europe) in 2013 and completed at the end of 2015. It included eleven international partners and the three important pilot cities Genoa, Florence, and Barcelona that, with another seven cities around Europe, laid the foundations for the development of light electric vehicles. From the very beginning, the relevance of the stakeholders' networking and the role of physical (e.g. charging points) and immaterial (e.g. policies and raising citizens' awareness) actions to be done was clear.

Finally, the city of Genoa renewed its membership of the Covenant of Mayors in 2018, a pact between eleven cities in order to reduce greenhouse gas emissions by at least $40 \%$ by 2030 .

\subsection{The ELVITEN Project in Genoa}

The experimentation with electric vehicles deals with different activities such as the monitoring of the range anxiety, in particular, and users' confidence in LEVs, in general, the question of recharging, the diffusion of sharing and the development of e-roaming and ICT tools.

In Genoa, the project promotes the use of LEVs, thanks to Kyburz, the supplier of ten electric L5e-A vehicles (tricycles), and private suppliers of one e-scooter and six e-quadricycles. Kyburz' tricycles have been conferred to public and private subjects in the Genoa area and are currently being used.

The testing in Genoa involves many ELVITEN partners such as:

- The Municipality of Genoa, which provides free parking for LEVs with the possibility of advanced booking and "bonuses" for virtuous behaviour;

- T Bridge, coordinating technical activities and developing ICT solutions;

- Quaeryon and Softeco, concerning ICT activities and 
- Duferco Energy, which provides the charging infrastructure and a dedicated app ("D-Mobility").

The pilot test started in May 2019 and the monitoring of the trips of the demonstration vehicles is still ongoing. For this purpose, each vehicle is equipped with a data logger (blackbox) in order to track every trip start, duration, and route.

The Genoese experimentation includes the implementation in strategic areas of the city of four charging points for two-, three-, and four-wheeled vehicles, which are integrated with the existing infrastructure. This measure promotes the development of a charging network in the city and the incentive for the adaptation of charging sockets in both public and private spaces.

The creation of the hubs has triggered a process of urban transformation, converting existing urban spaces to new functions. Parking spaces have been converted into a multimodal hub promoting inter-modality allowing citizens to use local and/ or private public transport and EVs.

Genoa has also initiated a process of civic involvement by linking mobility to the citizen. A plurality of ICT solutions is currently in phase of testing or development, such as:

- the booking of the charging points in the four Genoa hubs, thanks to the Duferco Energy "D-Mobility" mobile app, which allows the citizen to search, select, and book a charging point available, pay and monitor the charging;

- the monitoring of the EV fleet of tricycles with the blackboxes of the vehicle producer (Kyburz) and the following analysis made by the ELVITEN responsible partners;

- the booking and management of "positive incentives" to be given to citizens for their virtuous behaviours with regard to electric mobility, also to be used in other services proposed by the municipality and integrated in future in a wider rewarding logic for Smart-City citizens. For example, the possibility of offering free tickets for the local municipal museums is currently in progress. The system is implemented by the platform "Myeppi" $\left({ }^{2}\right.$, an outcome of the previous European project MOVEUS owned by Genoa Municipality, Quaeryon and Softeco, which has been adapted and customised for the ELVITEN needs.

For each ELVITEN Demonstration City, four types of specific solutions have been defined to carry out the demonstration through SERVICES, ICT TOOLS (e.g. apps, booking and brokering services), POLICIES promoted by public bodies and SPECIFIC COMMUNICATION/PROMOTION INITIATIVES.

The specific expected results, partially implemented, for Genoa are synthesised in Table 1.

\footnotetext{
${ }^{2}$ www.myeppi.com.
} 
Table 1 Solutions deployed in Genoa

\begin{tabular}{l|l}
\hline Services & $\begin{array}{l}\text { Creation of a widespread charging point network via the } \\
\text { installation of four e-charging hubs, including covered } \\
\text { shelters for electric bicycles and by integrating charging } \\
\text { points in private areas, open for public use } \\
\text { Integration of the charge network with the existing } \\
\text { infrastructure } \\
\text { Offering of ten three-wheelers by Kyburz for free use by local } \\
\text { logistics companies }\end{array}$ \\
\hline ICT Tools & $\begin{array}{l}\text { Brokering service for the shared three-wheelers and for } \\
\text { booking of charging points ("D-Mobility" app) } \\
\text { Management system for the e-charging hubs } \\
\text { LEV fleet monitoring tool and digital coach app }\end{array}$ \\
\hline Policies & $\begin{array}{l}\text { Genoa Municipality provides free parking in downtown } \\
\text { parking areas for LEVs, with the possibility of advance } \\
\text { booking } \\
\text { "Bonuses" for virtuous behaviour, as collected by the } \\
\text { Incentive Management App (platform "Myeppi"®) }\end{array}$ \\
\hline $\begin{array}{l}\text { Specific communication/ } \\
\text { promotion initiatives }\end{array}$ & $\begin{array}{l}\text { Genoa organises a permanent exhibition, in which LEV } \\
\text { providers present their products and inform visitors about the } \\
\text { state of art of LEVs } \\
\text { LEVs are offered to citizens for free testing }\end{array}$ \\
\hline
\end{tabular}

Source ELVITEN project, elaboration by authors

\subsection{Focus on Genoa Data}

The ELVITEN trips data (see Fig. 3) were collected before the COVID-19 period, showing the number of trips per month for all pilots up to February 2020. The total number of trips registered is 26,798 trips, of which 532 are active users. These are identified users who also participated in compilation of the questionnaires that were submitted by LEV-users during the monitoring activity of the project. The diagram shows a slow increase in the number of users after January.

The trip data collected by month presents an increasing peak of displacements in October 2019, highlighting that the testing of LEVs progressively increased as the demonstration was carried on. The winter period shows a not surprising decrease in the use of LEVs.

In the framework of the pilot experimentations, almost 1,000 questionnaires were filled out by LEV owners and users of shared vehicles. They highlighted that $88 \%$ of users of all pilot cities were satisfied with travelling on their LEVs and pointed out strong confidence in the use of LEVs as an alternative to ICE vehicles.

In Genoa, during the pilot period (up to February 2020, before the COVID-19 pandemic), more than 2,500 trips were made with the monitored ELVITEN LEVs (see Fig. 4) and 260 in March 2020 (see Fig. 5). These intermediate results, which are aligned with the other cities involved despite the poor attitude to use EVs in Genoa, show a good response of the citizens. 


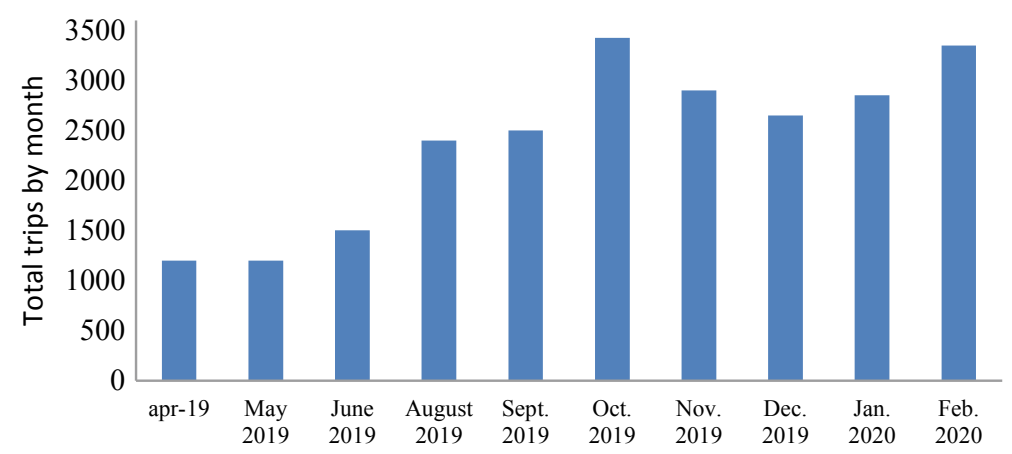

Fig. 3 Total trips per month for all pilot cities. Source ELVITEN project, 2020

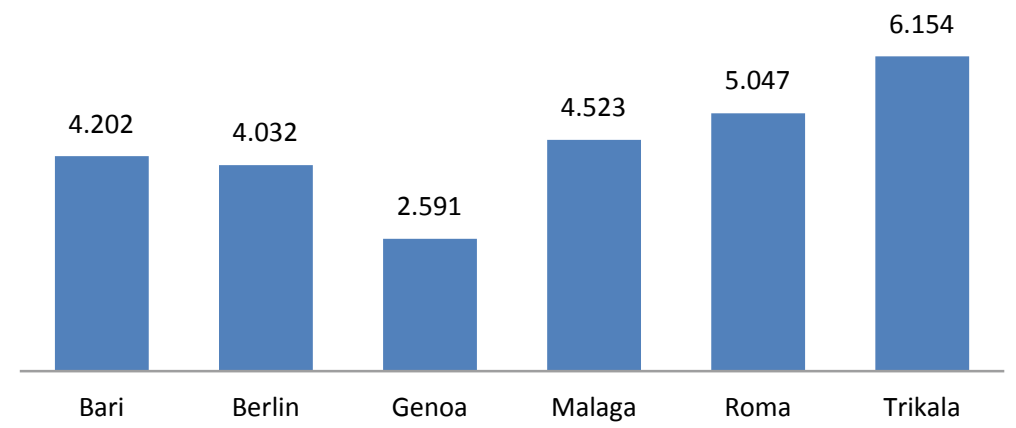

Fig. 4 Evolution by city of the total number of trips monitored (from May 2019 to February 2020). Source ELVITEN project, elaboration by authors

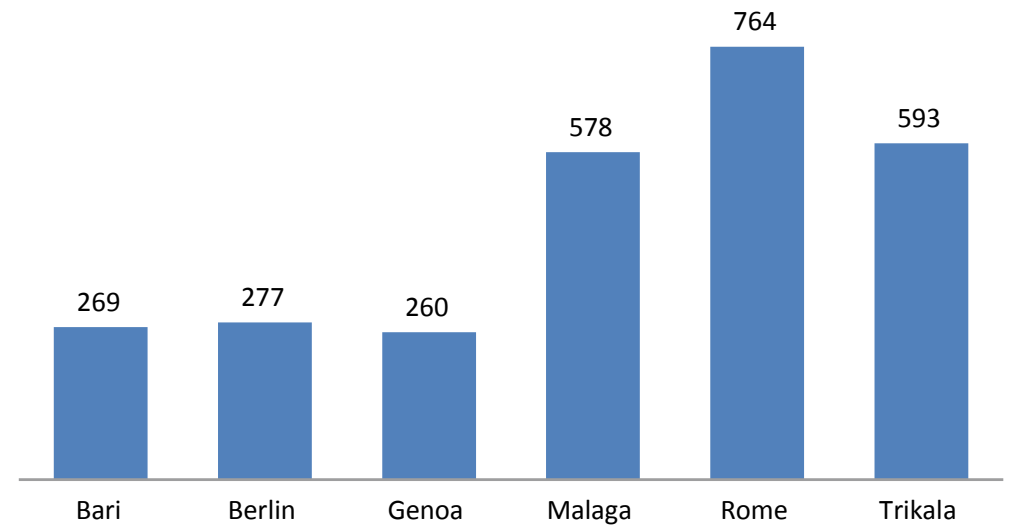

Fig. 5 Evolution by city of the number of trips monitored (March 2020). Source ELVITEN project, elaboration by authors 
The use of the ELVITEN LEVs in Genoa is characterised by one of the highest numbers of the average distance per trip that are registered in the pilot cities with more than $5.5 \mathrm{~km}$ (see Fig. 6).

Due to the geographical nature of the city, many trips are made within the urban area, characterised by a distance of $4-9 \mathrm{~km}$ and duration of less than $20 \mathrm{~min}$. However, some vehicles make trips in suburban areas covering a greater distance reaching $25 \mathrm{~km}$. Such a distance is also the major trip catchment area of the urban centre of Genoa (see Fig. 7). In consideration of the LEVs range equal to about $60 \mathrm{~km}$, the assumption that LEVs can replace ICE vehicles in urban and extra-urban areas under specific conditions is verified.

Regarding the average number of trips per user (a sort of utilisation rate) Genoa is peculiar. Indeed, while in most pilot cities sharing services were set up, in Genoa the 17-vehicle demonstration fleet (ten tricycles, one e-scooter and six e-quadricycles) has been assigned to specific users; consequently, we can notice a high average value of trips per user in comparison with other cities (see Fig. 8).

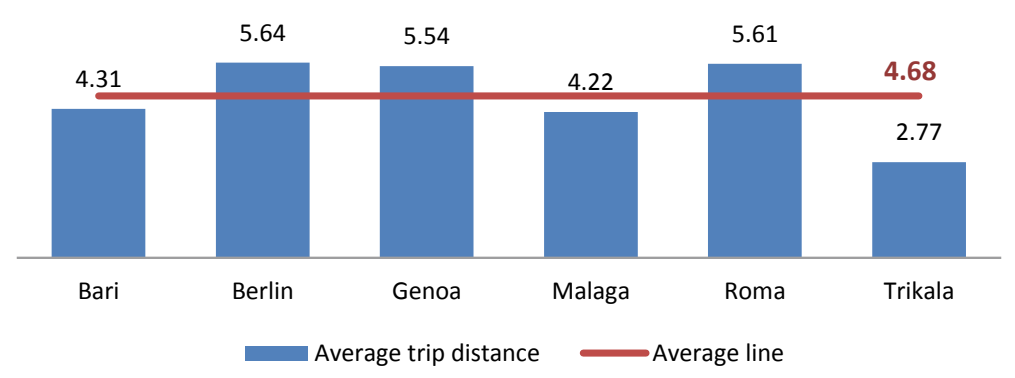

Fig. 6 Average distance per trip by city (up to February 2020). Source ELVITEN project, elaboration by authors

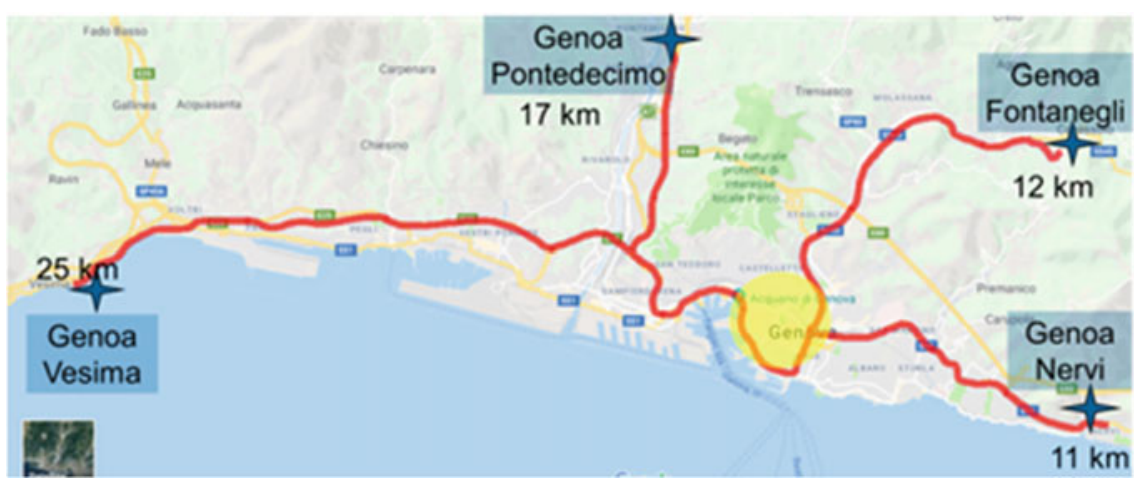

Fig. 7 Trip catchment area in Genoa. Source elaboration by authors 


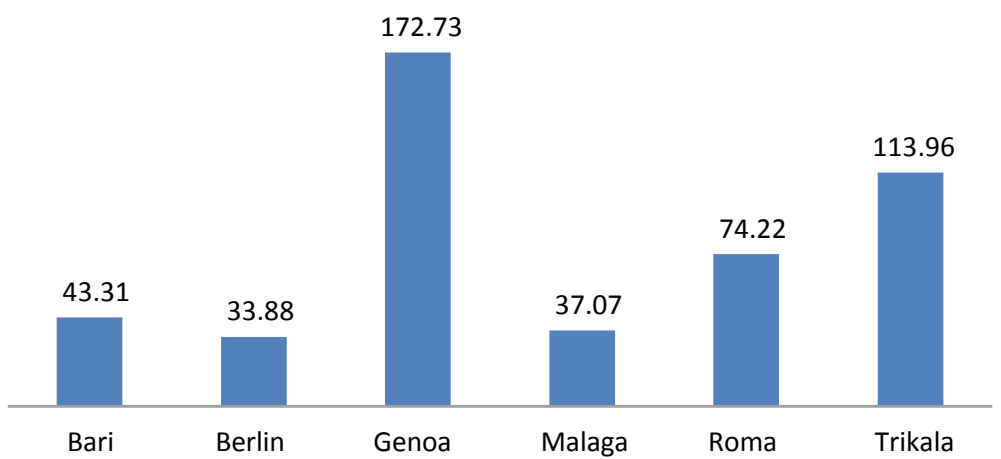

Fig. 8 Average number of trips per users. Source ELVITEN project, elaboration by authors

For all pilots, including Genoa, the day timeslot with the greatest number of trips registered is the morning time (10-13 o'clock with a quota of 32\%) and secondly the morning rush hours 7-10 o'clock (22\%) (see Fig. 9), highlighting the interesting share of the ELVITEN LEV use for leisure and more occasional trips than the usual journeys to get to offices or schools. In addition, the trips are made more often on weekdays (83\%) and less on the weekend (17\%) (see Fig. 10).

Fig. 9 Trips by timeslot. ELVITEN project, elaboration by authors

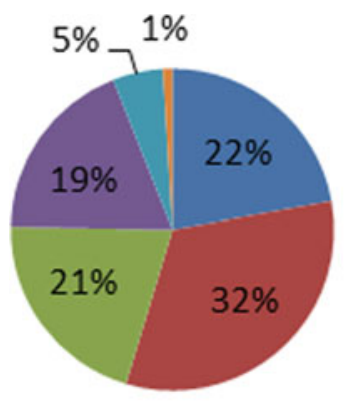

07-10h

10-13h

$13-16 h$

16-19h

$19-22 \mathrm{~h}$

22-07h

Fig. 10 Trips by day of the week. ELVITEN project, elaboration by authors

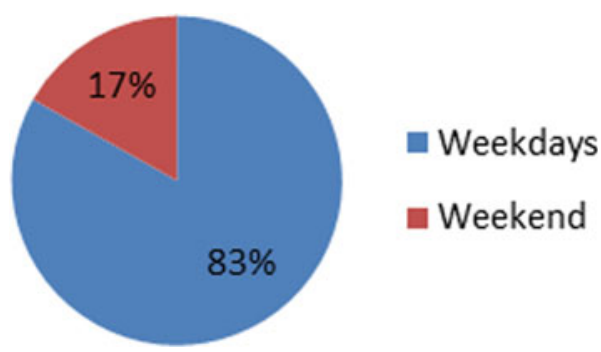


Table 2 Evolution by city of the number of trips per month monitored

\begin{tabular}{l|l|l|l|l}
\hline City & $\begin{array}{l}\text { Average trips/Month (start } \\
\text { pilot-Feb 2020) }\end{array}$ & $\begin{array}{l}\text { Trips in } \\
\text { March 2020 }\end{array}$ & $\begin{array}{l}\text { Trips in } \\
\text { April 2020* }\end{array}$ & $\begin{array}{l}\Delta \% \text { (March- } \\
\text { April 2020) (\%) }\end{array}$ \\
\hline Bari & 326 & 269 & 5 & -98 \\
\hline Berlin & 328 & 277 & 283 & 2 \\
\hline Genoa & 218 & 260 & 206 & -21 \\
\hline Malaga & 377 & 578 & 157 & -73 \\
\hline Rome & 571 & 764 & 295 & -61 \\
\hline Trikala & 511 & 593 & 397 & -33 \\
\hline Total & 2,331 & 2,741 & 1,343 & -51
\end{tabular}

*until 28 April

Source ELVITEN project, elaboration by authors

Finally, the monitoring of the number of trips carried out by LEVs in March and April 2020 (see Table 2) shows that in most of the pilot cities, the travel number decreased but not markedly, despite the spread of COVID-19 and the consequent blockage of travel. The figures for Genoa, in particular, show that despite a $21 \%$ decrease, it is lower than the other cities involved (average of 51\%).

\section{Conclusions: Challenges of LEVs}

The first results of the still ongoing ELVITEN project allow us to collect, analyse, and give relevant insights into the use of LEVs in everyday mobility. First, the specific pilot case of Genoa is showing that the consumers' concerns about the feeling of uncertainty with regard to the possible need to re-charge the vehicle during the trips (range anxiety) is less present than expected. Indeed, users who evaluated LEVs positively ( $88 \%$ of total pilot city users who filled in the questionnaires submitted) expressed that today the challenges facing LEVs are mostly related to the three following issues, listed approximately in order of priority from the citizens' point of view: cost, charging infrastructure and range. Only 3\% of shared LEV users and 3\% of the owners believe that the range anxiety is the most critical challenge to overcome today in order to make possible and convenient the use of LEVs.

The evidence that the range anxiety is not the first challenge to be tackled in an urban context, such as Genoa, also concern the distance covered per trip, which, as previously highlighted, in Genoa is relatively higher than those usually covered by such vehicles (an average of $5.5 \mathrm{~km}$, with trips reaching $25 \mathrm{~km}$ ).

The results of the still ongoing ELVITEN experience are showing that working towards putting in place an integrated system of charging infrastructure (in Genoa by four new charging hubs in the most attractive points of the city) and incentives (set of policies offered and reward systems for the users) supports the use of LEVs. 
In this light, the characteristics of LEV trips, in terms of, for example, number, distance covered, or utilisation rate, are not strongly affected by the impacts of the constraints due to the COVID-19 pandemic.

Acknowledgements This paper and the research behind it would not have been possible without the participation of T Bridge in the ELVITEN project. We thank our project partners (https://www. elviten-project.eu/en/about/) for allowing us to use the project data to produce this paper. We would also like to thank our colleagues Michele Solari and Simone Porru from T Bridge, the Duferco Energy project partner, who have undoubtedly contributed to the interpretation of the data in this paper.

Funding for this research was provided by the HORIZON 2020 project "ELVITEN".

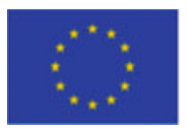

This project has received funding from

the European Union's Horizon 2020

research and innovation programme

under grant agreement № 769926 .

\section{References}

1. ELVITEN homepage: https://www.elviten-project.eu/it/. Last Accessed 22 April 2020

2. ISTAT homepage: http://dati.istat.it. Last Accessed 22 April 2020

3. Motus-e Homepage: (2019). https://www.motus-e.org. Last Accessed 22 April 2020

4. The European House Ambrosetti, Motus-e (in collaboration with): La filiera della mobilità elettrica "Made in Italy". (2019). https://www.motus-e.org/wp-content/uploads/2019/07/ 1907_Executive-Summary_La-filiera-e-Moblity-in-Italia.pdf

5. ANCMA Homepage: http://www.ancma.it/statistiche/. Associazione Nazionale Ciclo Motociclo e Accessori. Last Accessed 22 April 2020

6. Motus-e.: Le Infrastrutture di ricarica pubbliche in Italia (2020) https://www.motus-e.org/wpcontent/uploads/2020/03/Report-IdR_Marzo_MOTUS-E.pdf

7. MIT Homepage: http://dati.mit.gov.it. Last Accessed 22 April 2020

8. Il Ministro delle Infrastutture e dei Trasporti: (2019) M_INF.GABINETTO.REG_DECRETI. R.0000229.04-06-2019. http://www.mit.gov.it/sites/default/files/media/notizia/2019-06/ schema\%20DM\%20micromobilit\%C3\%A0\%20229_2019\%20\%283\%29.pdf. Last Accessed 24 Aug 2020

9. Il Ministro delle Infrastutture e dei Trasporti: (2012) Piano Nazionale Infrastutturale per la Ricarica die veicoli alimentati ad energia Elettrica. http://www.governo.it/sites/governo.it/ files/PNire.pdf. Last Accessed 24 Aug 2020

10. Regulation (EU) No 168/2013 of the European Parliament and of the Council of 15 January 2013 on the approval and market surveillance of two- or three-wheel vehicles and quadricycles. https://eur-lex.europa.eu/legal-content/EN/ALL/?uri=CELEX\%3A32013R0168. Last Accessed 24 Aug 2020

11. European Commission: Transport 2050: Commission outlines ambitious plan to increase mobility and reduce emissions. (2011). https://ec.europa.eu/commission/presscorner/detail/en/ IP_11_372. Last Accessed 24 Aug 2020

12. Reyes Garcia, J.R., Lenz, G., Haveman, S.P., Bonnema, G.M.: State of the art of electric Mobility as a Service (eMaaS): an overview of ecosystems and system architectures. In: 32nd International Electric Vehicle Symposium (EVS32) (2019) 
13. ACI Homepage: (2019) http://www.aci.it/ ACI Automobile Club d'Italia. Last Accessed 22 April 2020

14. Automobile Club d'Italia: Autoritratto 2019. (2019) http://www.aci.it/laci/studi-e-ricerche/ dati-e-statistiche/autoritratto/autoritratto-2019.html. Last Accessed 03 July 2020

Open Access This chapter is licensed under the terms of the Creative Commons Attribution 4.0 International License (http://creativecommons.org/licenses/by/4.0/), which permits use, sharing, adaptation, distribution and reproduction in any medium or format, as long as you give appropriate credit to the original author(s) and the source, provide a link to the Creative Commons license and indicate if changes were made.

The images or other third party material in this chapter are included in the chapter's Creative Commons license, unless indicated otherwise in a credit line to the material. If material is not included in the chapter's Creative Commons license and your intended use is not permitted by statutory regulation or exceeds the permitted use, you will need to obtain permission directly from the copyright holder.

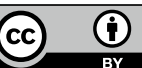

